\title{
The development of strategic manufacturing capabilities in emerging and developed markets
}

\author{
Andreas Größler
}

Received: 16 September 2009 /Revised: 20 October 2009/Accepted: 1 March 2010 /Published online: 23 March 2010

(C) The Author(s) 2010. This article is published with open access at Springerlink.com

\begin{abstract}
The purpose of this exploratory paper is to find differences in the occurrence of and the relationships between strategic capabilities for manufacturing firms in developed and emerging markets. To this end, a longitudinal approach is taken, and developments of capability structures in the two types of markets over time are analysed. By concentrating on strategic capabilities, this paper adds to the sparse literature on operations' globalisation taking a resource-based, internal perspective.
\end{abstract}

Keywords Strategic capabilities · Emerging markets · Longitudinal study $\cdot$ Manufacturing strategy

\section{Strategic capabilities in emerging and developed markets}

Strategic manufacturing capabilities are the contribution of the operations function to the competitive success factors of a company; strategic capabilities are the strengths of a firm with which it supports corporate strategy and which help it succeed in the market place. The identification and development of strategic capabilities are a major task of manufacturing strategy (Slack and Lewis 2002). Capabilities allow an enterprise to exploit resources in order to generate profit through its products and services (Amit and Schoemaker 1993). With the help of its capabilities, an organisation transforms input factors into products and services (Warren 2007). A differentiation is made between four classic strategic capabilities: The ability to (1) produce at a low cost, (2) yield high quality products, (3) ensure a reliable delivery and (4)

\section{A. Größler $(\bowtie)$}

Institute for Management Research,

Radboud University Nijmegen,

P.O. Box 9108, 6500 HK Nijmegen, The Netherlands

e-mail: a.groessler@fm.ru.nl maintain flexibility concerning mix and volume of products (Wheelwright 1984). Therefore, this paper-as most other articles in this area-concentrates on these four capabilities, despite the fact that the existence of other capabilities is conceivable, likely, or will become important in the future.

The purpose of this exploratory paper is to find differences in the occurrence of and the relationships between strategic capabilities for manufacturing firms in developed and in emerging markets. In order to achieve this, a longitudinal approach is taken and developments of capability structures in the two types of markets are analysed over time. Although longitudinal analyses are often called for, with the objective of investigating the dynamics of capability developments (e.g., Swink and Way 1995), only little empirical work has been done in this area.

An exception is Lapré and Scudder (2004), who analyse ten US airline companies over a period of eleven years regarding their performance improvement paths. They found that whether firms follow a sand cone model or experience trade-offs between their capabilities depends on the distance to their asset frontier. In line with Porter's (1996) and Schmenner and Swink's (1998) theoretical considerations, firms further away from the asset frontier can improve on more than one capability at the same time; firms closer to the asset frontier can improve in one capability only.

Also concentrating on the issue of strategic capabilities, this article provides a highly aggregated and abstract picture using a large scale questionnaire approach. Due to the international scope of the questionnaire and the four rounds the study has been conducted since 1993, the dynamics of capability relationships can be studied for firms in two types of markets, while still maintaining a longitudinal perspective. Thus, companies from emerging and developed economies are compared.

For instance, one hypothesis that can be tested with this approach is that the structure of strategic capabilities in 
emerging market firms lags a few years behind the structure of the capabilities in developed market firms. With its concentration on strategic capabilities, this paper adds to the sparse literature on operations' globalisation that takes a resource-based, internal perspective (Carr 1993; Collis 1991). Issues of global supply chain configurations (e.g., Cagliano et al. 2008) or global purchasing and sourcing (e.g., Leonidou 1999) are discussed elsewhere.

The structure of the paper is as follows. The IMSS project and databases are presented in the second section. Results of the longitudinal analyses are presented and discussed in the two following sections; three practical implications of the article are put forward. The fifth section provides a short discussion of limitations, along with the formulation of research questions resulting from this exploratory study.

\section{The international manufacturing strategy survey project}

In this study empirical data is drawn from the International Manufacturing Strategy Survey (IMSS). IMSS has been run four times to date: in 1993, 1998, 2002, and 2006, allowing for a longitudinal investigation. The questionnaire contains items on strategic objectives and programmes, on the organizational and environmental context of management and on performance figures of manufacturing plants from ISIC codes 28-35 (machinery; tools; electrical, electronic and optical devices; measurement devices; transportation facilities). Some questionnaire items as well as some participating companies have been included all four rounds of IMSS, which allows for a strict longitudinal analysis (Goldstein 1979; for an example see Cagliano et al. 2005). Additionally, samples of the different rounds can be assumed to be representative of the population of firms within the examined industries, thus making longitudinal comparisons of mean values between total samples possible as well. The analyses in the paper follow the latter approach, analysing trends in the data.

Most items in the questionnaire come in the form of perceptual measures (Ketokivi and Schroeder 2004). The sampling method was convenience sampling with some random participants; the questionnaires were filled out in the participants' companies, free from influence by the researchers (self-administered study); questionnaires were sent out by mail or fax, frequently after contact had been established by phone. Sample sizes are: 573 for IMSS-1, 445 for IMSS-2, 465 for IMSS-3, and 656 for IMSS-4.

Table 1 shows how strategic capabilities are composed of various questionnaire items (not all items were used in each round of the survey; original questionnaire items are given in the appendix). Items were taken from question D1 (IMSS-1 and IMSS-2), D2 (IMSS-3) and B9 (IMSS-4).
With the exception of IMSS-2, the items ask for changes over the last three years in detailed capabilities. Thus, IMSS does not describe the current state of capabilities but rather the way in which they had been developing in the three years before the questionnaire was sent out. In IMSS-2, the importance of the detail capability is asked for directly, which is in line with the needs of this analysis. In IMSS-2 to IMSS-4 respondents had to answer on a 5 point Likert scale; in IMSS-1, respondents had to estimate changes as percentages of improvement or decline.

In most cases, several items of the IMSS questionnaire are used to represent the four manufacturing capabilities in question, emphasising the multidimensional nature of manufacturing capabilities (Flynn and Flynn 2004). The items are combined to represent manufacturing capabilities following conceptual considerations based on standard texts from the field (Slack et al. 2007; Heizer and Render 2008; Bozarth and Handfield 2008; Krajewski et al. 2010). Thus, the following capability scores are rather representative indices justified by prior literature than statistical factors. This approach was chosen, since the construction of statistically valid factors of capabilities was not the objective of this study. Rather, this paper explores developments based on intuitive definitions of what strategic capabilities are comprised of. By this procedure, the potential drawbacks of such "common sense" definitions are not neglectedhowever, a conclusive definition of strategic capabilities is left for further study (for an attempt to this end, see Größler and Grübner 2006).

Based on this structure of strategic capabilities, development paths for plants in emerging and developed markets are compared in the rest of this paper. To this end, the samples were split into two groups of 'emerging' and 'developed' markets by using MSCI equity market indices (http://www.msci.com/coverage/index.html). This resulted in a different number of companies located in emerging markets than that in developed markets (Table 2).

\section{Results of longitudinal analyses}

In this section, two different analyses are presented that are based on the differentiation of companies belonging to either emerging or developed markets: (i) changes in the relative importance given to the four capabilities of the two market types, and (ii) differences in capability relevance between the markets.

For both analyses, strategic manufacturing capabilities are operationalised using the IMSS items as indicated in Table 1. For each strategic capability, the average of the corresponding item values across all companies was calculated. It must be noted that the item format in IMSS- 
Table 1 IMSS items identified as indicating manufacturing capabilities with codes given for the respective questionnaire

\begin{tabular}{|c|c|c|c|c|c|}
\hline Manufacturing capability & Item & IMSS-1 (1993) & IMSS-2 (1998) & IMSS-3 (2002) & IMSS-4 (2006) \\
\hline \multirow[t]{3}{*}{ Quality } & Manufacturing conformance & D1 & D14 & D21 & B9A \\
\hline & Product quality and reliability & - & - & D22 & B9B \\
\hline & Delivery reliability & D9 & D117 & D29 & B9L \\
\hline \multirow[t]{3}{*}{ Time } & Time to market & D7 & D16 & D26 & B9F \\
\hline & Delivery speed & D23 & D115 & D28 & B9I \\
\hline & Manufacturing lead time & D19 & D112 & D210 & B9N \\
\hline \multirow[t]{3}{*}{ Flexibility } & Product customisation ability & - & - & D23 & B9C \\
\hline & Volume flexibility & - & - & D24 & B9D \\
\hline & Mix flexibility & D25 & D15 & D25 & B9E \\
\hline \multirow[t]{5}{*}{ Cost } & Labour productivity & - & - & D213 & B9Q \\
\hline & Inventory turnover & D5 & D116 & D214 & B9R \\
\hline & Capacity utilisation & - & - & D215 & B9S \\
\hline & Overhead costs & - & D111 & D216 & B9T \\
\hline & Unit manufacturing cost & - & - & - & B9M \\
\hline
\end{tabular}

1 is different than the format in the other three IMSS rounds: in IMSS-1 respondents are asked for changes in percentages; in IMSS-2 to IMSS-4 respondents are asked for changes based on a five point Likert scale, ranging from "substantially decreased" to "substantially increased".

Therefore, in order to compare results for the different IMSS rounds, the weight of a capability in relation to all other capabilities was calculated. These weights indicate the relevance and the emphasis put on a specific capability by management, as compared to the other three strategic capabilities. In the weighting algorithm, the averages of the four capability values for both types of companies (emerging and developed markets) were compared, leading to eight capability values. The value 1.0 was assigned to the lowest of these capabilities; the other capabilities were scaled proportionally. For example, in IMSS-2 (1998) the average of the flexibility capability in developed markets is 2.34. Since this is the lowest of all average values of capabilities for this survey round, a weight of 1.0 was

Table 2 Number of companies in emerging and developed group for the four samples

\begin{tabular}{rcc}
\hline & $\begin{array}{l}\text { Companies in emerging } \\
\text { markets (in brackets: } \\
\text { number of countries) }\end{array}$ & $\begin{array}{l}\text { Companies in developed } \\
\text { markets (in brackets: } \\
\text { number of countries) }\end{array}$ \\
\hline $\begin{array}{r}\text { IMSS-1 } \\
(1993)\end{array}$ & $137(4)$ & $463(16)$ \\
$\begin{array}{r}\text { IMSS-2 } \\
(1998)\end{array}$ & $223(8)$ & $477(15)$ \\
$\begin{array}{r}\text { IMSS-3 } \\
(2002)\end{array}$ & $140(3)$ & $386(12)$ \\
$\begin{array}{r}\text { IMSS-4 } \\
(2006)\end{array}$ & $207(6)$ & $453(15)$ \\
\hline
\end{tabular}

assigned. The average for the cost capability in emerging markets, for instance, is 3.02 . The weight corresponding to this average value is $3.02 / 2.34=1.29$. This weight calculation was applied to all four capabilities of the two market types for the four IMSS rounds.

This procedure and the results can be explained using the uppermost graph in Fig. 1, which depicts the development of the weights for the quality capability. Quality started out as an important capability (values above 2 for emerging and developing market companies) as compared to other capabilities in 1993. Until the end of the investigated time span (2006), the weight of quality had decreased to just above one, indicating that by then quality did not get much more emphasis than the least important capability. Again, this result basically holds for both types of markets, with a slightly higher relevance for quality in emerging market firms (the weight of quality for emerging markets in 2006 is about 1.2, for developed markets about 1.1).

The fundamental behaviour of the time and the cost capability are similar to quality, as can be seen in the rest of Fig. 1. These three capabilities started with a high weight compared to at least one other capability, which was flexibility in 1993 and 1998. From 2002 onwards, all four capability weights are close to 1.0 (i.e. the lowest possible value), with the highest value of 1.2 (meaning that the associated capability is roughly $20 \%$ more important for the companies). This indicates that in the later IMSS rounds no big differences can be observed concerning the emphasis placed on the different capabilities.

Concerning the differences in the relevance of strategic capabilities between emerging and developing markets, it can be stated that in the last two IMSS rounds (2002 and 2006) emerging market companies achieved higher values than their developed markets counterparts. With the exception of the 

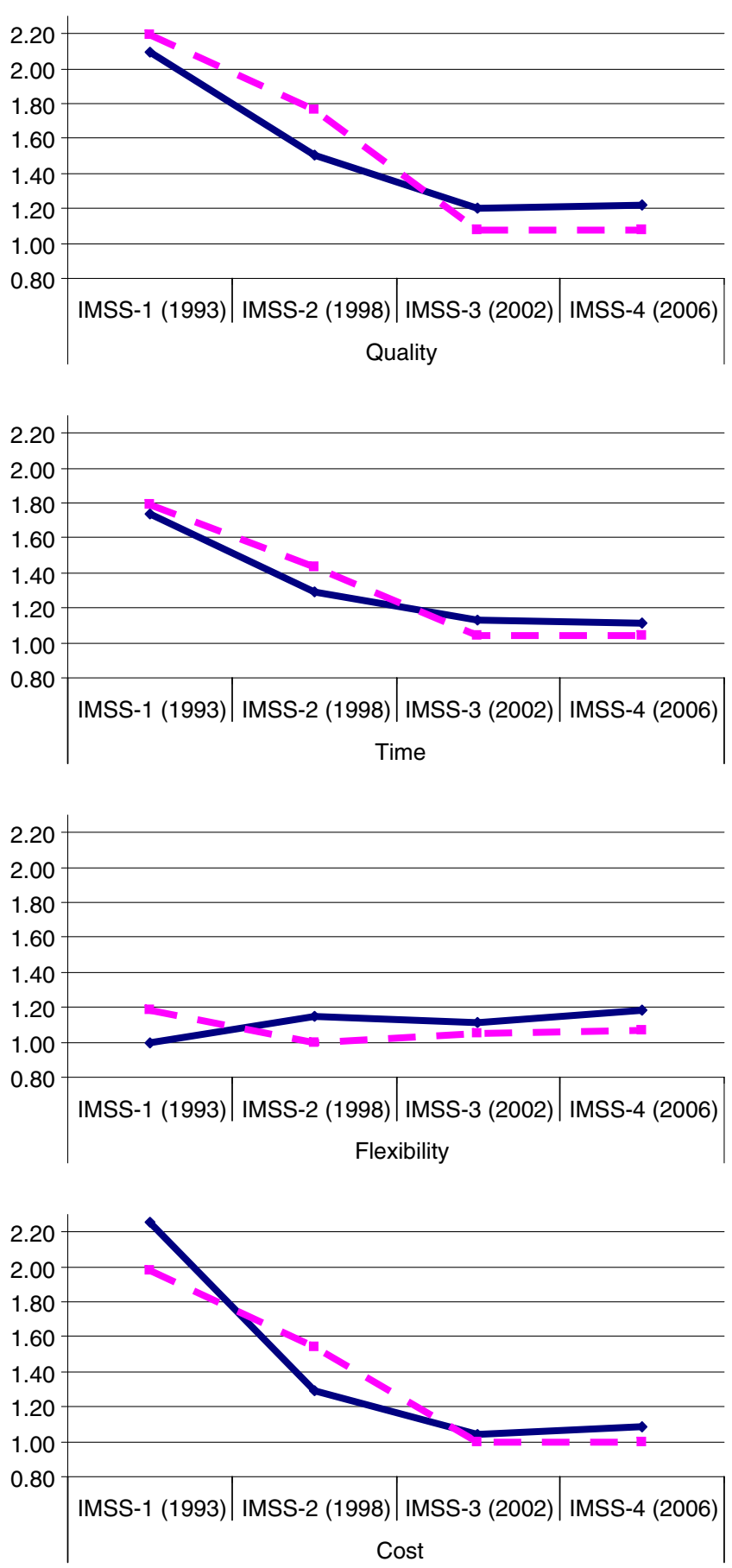

Fig. 1 Development of importance of strategic capabilities for emerging markets (solid line) and developed markets (dashed line)

cost capability, this is different for the first IMSS round (in 1993): developed market companies achieve higher capability values than companies from emerging markets. The cost capability seems always to have been the major emphasis of emerging market companies as compared to developed market companies (with the exception of 1998).

Differences between companies in emerging and developed markets become clearer, when considering Fig. 2. The figure shows the capability weights for the four capabilities, separated for each of the four IMSS rounds, starting with IMSS-1. Again, it can be observed that flexibility is the least relevant strategic capability at the beginning of the period, with the other capabilities showing a decrease in their relative weight towards the end of the period (or, more precisely, all four capabilities become equally important).

Significant differences between the capability relevance in the two market types are indicated by an asterisk. These

IMSS-1 (1993)

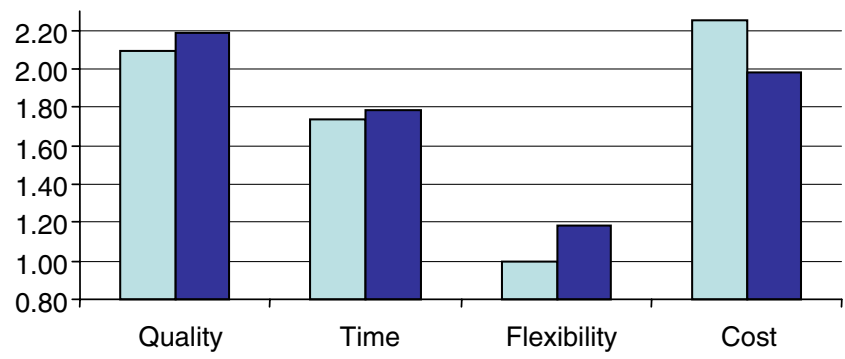

IMSS-2 (1998)

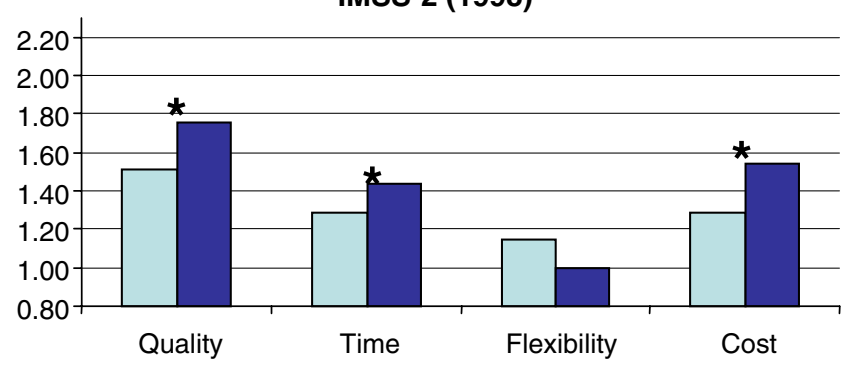

IMSS-3 (2002)

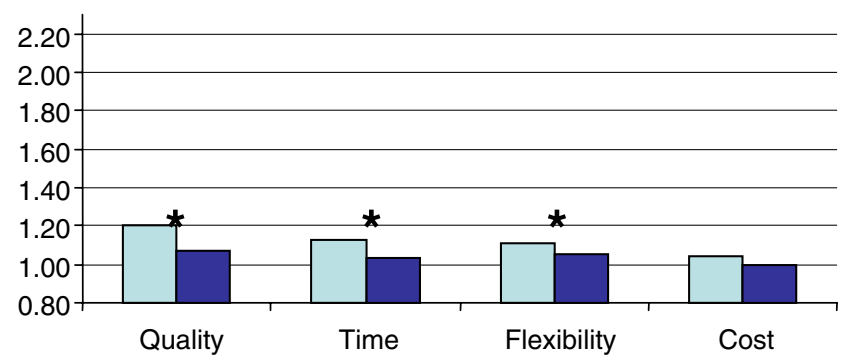

IMSS-4 (2006)

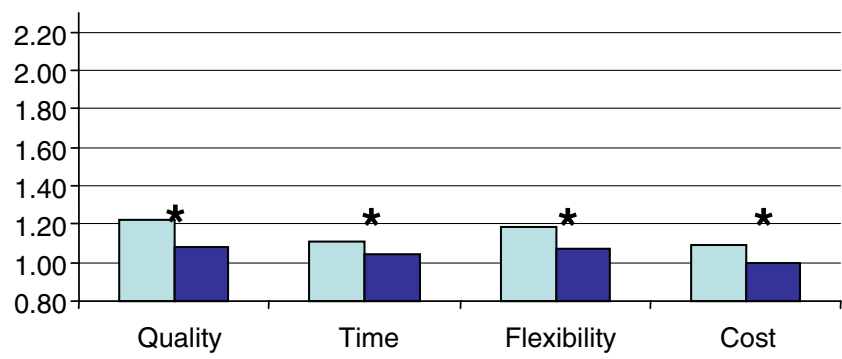

Fig. 2 Weight of strategic capabilities over time for emerging markets (left pillars) and developed markets (right pillars); * indicates significant differences (with at least $p<0.05$ ) between emerging and developed market companies 
differences were calculated based on a $t$-test, using the capability values of the two groups of companies as input data. Table 3 shows the results of these statistical tests in more detail. The table shows the averages for the four capabilities and the significance level of the differences.

Differences between the two market types seem to have grown over the years. While for 1993 no differences can be confirmed statistically, there are three significant differences in capabilities in the following two IMSS rounds. In the last round (IMSS-4 in 2006), even all four capabilities are significantly different in emerging and developed market firms (with emerging market firms attributing higher relevance to all capabilities than developed market firms in later rounds of the survey).

\section{Interpretation of results and practical implications}

When interpreting these results, one has to keep in mind two characteristics of the analyses in this paper. First, a lower capability weight does not necessarily mean that the absolute relevance of this capability is decreasing; only the relevance in relation to other capabilities has decreased. Second, changes in capability achievement are interpreted as the relevance perceived and the emphasis put on the capabilities by management (with the exception of IMSS-2, where this is directly asked for). Thus, the assumption is made that increases in capability achievement did not occur randomly but were an effect of deliberate management decisions.

Without first concentrating on the differences between emerging and developing markets, one can describe the shift in terms of the relative relevance between the four strategic manufacturing capabilities from 1993 to 2006. At the beginning of this period, the cost and quality capabilities were the most important. Flexibility did not play a substantial role, and time held a median position between the two highly regarded capabilities and the neglected capability, flexibility. This has changed towards the end of the observation interval: all capabilities are becoming equally important, which basically means that flexibility is now accepted as a fourth standard capability of manufacturing firms (for a discussion of capability structures see, for example, Ferdows and de Meyer 1990; Flynn and Flynn 2004; Rosenzweig and Roth 2004; Größler and Grübner 2006).

The analyses show that emerging market firms have closed the gap between them and the developed market companies in the relevance they attribute to the four capabilities. While at the beginning of the 1993-2006 period, emerging market firms lagged behind in all but one capability (cost), by the end of the period these companies attributed even higher relevance to all capabilities than developed market firms. The one exception to this general observation is the cost capability: in 1993 in particular, cost seems to be the strategic capability with which emerging market manufacturers wanted to compete (although the difference is not statistically significant). However, this has changed over the years into a balanced focus on of all four capabilities by emerging market companies and developed market companies alike.

The exemplary hypothesis described above (that the structure of strategic capabilities in emerging market firms lags a few years behind the structure of the capabilities in developed market firms) could not be supported by this analysis. For instance, the increasing relevance of flexibility as a fourth strategic capability appears to occur in both market types around the same time: flexibility seems to be less relevant in 1993 and 1998, while in 2002 and 2006 it
Table 3 Differences in strategic capabilities between companies in emerging and developed markets. Note differences in scales between IMSS-1 and the other three rounds

\begin{tabular}{|c|c|c|c|}
\hline & & Emerging market companies & Developed market companies \\
\hline \multirow[t]{4}{*}{ IMSS-1 (1993) } & Quality & 23.73 & 24.82 \\
\hline & Time & 19.70 & 20.26 \\
\hline & Flexibility & 11.33 & 13.45 \\
\hline & Cost & 25.53 & 22.39 \\
\hline \multirow[t]{4}{*}{ IMSS-2 (1998) } & Quality $^{\mathrm{a}}$ & 3.53 & 4.12 \\
\hline & Time $^{\mathrm{a}}$ & 3.02 & 3.56 \\
\hline & Flexibility & 2.53 & 2.34 \\
\hline & $\operatorname{Cost}^{\mathrm{a}}$ & 3.02 & 3.61 \\
\hline \multirow[t]{4}{*}{ IMSS-3 (2002) } & Quality $^{\mathrm{a}}$ & 3.79 & 3.39 \\
\hline & Time $^{\mathrm{a}}$ & 3.56 & 3.27 \\
\hline & Flexibility $^{\mathrm{b}}$ & 3.49 & 3.32 \\
\hline & Cost & 3.29 & 3.15 \\
\hline \multirow[t]{4}{*}{ IMSS-4 (2006) } & Quality $^{\mathrm{a}}$ & 3.14 & 2.77 \\
\hline & Time $^{\mathrm{a}}$ & 2.86 & 2.68 \\
\hline & Flexibility $^{\mathrm{a}}$ & 3.04 & 2.75 \\
\hline & $\operatorname{Cos}^{\mathrm{a}}$ & 2.80 & 2.57 \\
\hline
\end{tabular}

${ }^{\mathrm{a}}$ indicates a significant difference at $p<0.01$

${ }^{\mathrm{b}}$ indicates a significant difference at $p<0.05$ 
has basically the same relevance as the other three capabilities in both types of markets, emerging and developed. There is no delay to be observed concerning changes in the capability structure in emerging markets. This study shows that manufacturing firms in emerging markets have caught up with their counterparts from developed markets with regard to strategic capabilitiesboth groups of companies try to increase all four manufacturing capabilities in a similar fashion, with the emerging market group showing higher increase rates.

The practical implications are threefold. First, manufacturing firms - regardless of whether these are located in emerging or developed market countries - can no longer concentrate on a single strategic capability (as, for instance, emerging market companies have done with cost in the past). Being competitive requires pursuing all four capabilities with some (but not necessarily equal) emphasis. The apparently minor differences between the relevance companies attribute to the four capabilities reflect their limited resources; in a world without resource restrictions companies could strongly improve all capabilities simultaneously and to the same degree. With resource limitations, emphasising one capability over another allows for strategic differentiation and firms have to choose on which capabilities they will focus. For instance, in IMSS-4 (2006) firms in both types of markets have emphasised the quality and flexibility capabilities in contrast to cost and time.

Second, the differences regarding the relative importance of capabilities have decreased over time: the four classic capabilities: quality, cost, time, and flexibility, have grown increasingly similar with respect to the relevance that companies attribute to them. As one can see from the analysis in this study, the capabilities show an increasing approximation to a value of 1.0, a trend which indicates indifference between capabilities relevance. Thus, being able to compete successfully in future might require identifying, developing and exploiting one or more new strategic capabilities (like innovativeness), in order to differentiate from the bulk of competitors.

Third, capability differences between companies in emerging markets and those in developed markets diminish. In particular, firms in developed markets should not assume that firms in emerging markets lag behind in the four capabilities - even if the current state of their capabilities might be below the achievement levels of developed market firms (an assumption which can neither be supported nor rejected based on this study), emerging market firm capabilities show a higher growth. Thus, it is only a matter of time before emerging market companies will have caught up with their developed market counterparts. It may even be assumed that emerging market firms can exploit the fact that they started later than developed market firms, learn from the latter's development, and avoid mistakes.

\section{Conclusions}

The limitations of this longitudinal study are for a large part a result of the design of the IMSS questionnaires and the data collection method used. Although the questionnaire featured an item on the change (and thus the relevance) of capabilities in all four rounds of the IMSS project, the concrete item formulation and scales have changed slightly over the years. Working with weights that put the capabilities in relation instead of working with actual capability values mitigates the problems resulting from this change in item formulation. Furthermore, although longitudinal from the outset, IMSS only allows for trend analyses whenever a substantial sample size is required, since the sample of companies changes between rounds (with only a limited number of companies being kept). A panel design (with a fixed sample of companies investigated over time) might yield additional insights.

Another limitation results from the use of a questionnaire, i.e. firms can obviously only provide answers to questions that have been asked. This means that new developments might be missed, for instance the appearance of a novel strategic capability that firms are trying to develop (e.g. innovativeness). Like flexibility, these novel capabilities might be rather underrepresented in the beginning but become more prevalent over time.

A research agenda shedding more light on the issues of this article includes, for instance, further statistical analysis with IMSS data; in particular path modelling might be useful to explore the structure of capabilities in emerging and developed markets. In a similar fashion, the findings of this study could be connected with other data from IMSS or from external data sources to check for moderating effects, like company size. In the near future, IMSS-5 data will be available that can be incorporated into the analysis; the data set will become available in the course of 2010 . With the availability of this data set, the possibilities of running panel studies and of using a stable questionnaire format will increase as well, at least for the last three rounds of IMSS. Since the sheer number of items that might represent strategic capabilities has increased over time, the later rounds (including IMSS-5) probably allow for the identification of new strategic capabilities that were not covered in earlier questionnaires. Finally, future studies into the development of strategic capabilities might be enriched by qualitative analyses of firms in emerging and developed countries and by the application of other methods than statistics, for instance simulation modelling. Following this research agenda, further insights into the structure and dynamics of strategic manufacturing capabilities in emerging as well as in developed market companies may be expected.

Open Access This article is distributed under the terms of the Creative Commons Attribution Noncommercial License which per- 
mits any noncommercial use, distribution, and reproduction in any medium, provided the original author(s) and source are credited.

\section{Appendix A: Questionnaire items}

This appendix contains the original questionnaire items from the four IMSS rounds used in this article.

\section{$\underline{\text { IMSS-1 (1993) }}$}

D. In the following list, we ask you to mentally construct an index for each manufacturing performance indicator. We ask you to assume that the beginning of 1990 is the base with index 100. How large would you estimate that the percentage change in the index today (1992) would be?

Change in percentage

\begin{tabular}{lll}
\hline D1 & Conformance to specification (manufacturing quality) & - \\
D5 & Inventory turnover & - \\
D7 & Speed of product development & - \\
D9 & On-time deliveries & - \\
D17 & Customer service & - \\
D23 & Delivery lead time & - \\
D25 & Product variety &
\end{tabular}

\section{IMSS-2 (1998)}

D1.

(1= very low; $5=$ Importance

D14 Conformance to specification (manufacturing quality)

D15 Product variety

D16 Speed of product development

D111 Materials and overhead total costs

D112 Manufacturing lead time

D115 Delivery lead time

D116 Inventory turnover (sales / inventory)

D117 On-time deliveries

\section{IMSS-3 (2002)}

D2. Please indicate the amount of change of the following performance dimensions over the last three years

\begin{tabular}{|c|c|c|c|c|c|c|}
\hline & & $\begin{array}{c}\begin{array}{c}\text { Strongly } \\
\text { deteriorated }\end{array} \\
\end{array}$ & \multicolumn{2}{|c|}{$\begin{array}{c}\text { No } \\
\text { change }\end{array}$} & \multicolumn{2}{|c|}{$\begin{array}{c}\text { Strongly } \\
\text { improved }\end{array}$} \\
\hline $\mathrm{D} 21$ & Manufacturing conformance & 1 & 2 & 3 & 4 & 5 \\
\hline D22 & Product quality and reliability & 1 & 2 & 3 & 4 & 5 \\
\hline D23 & Product customization ability & 1 & 2 & 3 & 4 & 5 \\
\hline D24 & Volume flexibility & 1 & 2 & 3 & 4 & 5 \\
\hline D25 & Mix flexibility & 1 & 2 & 3 & 4 & 5 \\
\hline D26 & Time to market & 1 & 2 & 3 & 4 & 5 \\
\hline D28 & Delivery speed & 1 & 2 & 3 & 4 & 5 \\
\hline D29 & Delivery reliability & 1 & 2 & 3 & 4 & 5 \\
\hline D210 & Manufacturing lead time & 1 & 2 & 3 & 4 & 5 \\
\hline D213 & Labor productivity & 1 & 2 & 3 & 4 & 5 \\
\hline D214 & Inventory turnover & 1 & 2 & 3 & 4 & 5 \\
\hline D215 & Capacity utilization & 1 & 2 & 3 & 4 & 5 \\
\hline D216 & Overhead costs & 1 & 2 & 3 & 4 & 5 \\
\hline
\end{tabular}

IMSS-4 (2006)

B9. How has your operational performance changed over the last three years?

\begin{tabular}{|c|c|c|c|c|c|c|}
\hline & & \multicolumn{5}{|c|}{ Compared to three years ago the indicator has } \\
\hline & & $\begin{array}{c}\text { deteriorated } \\
\text { more than } 10 \%\end{array}$ & $\begin{array}{l}\text { stayed about } \\
\text { the same }\end{array}$ & $\begin{array}{l}\text { improved } \\
10 \%-30 \%\end{array}$ & $\begin{array}{l}\text { improved } \\
\mathbf{3 0 \% - 5 0 \%}\end{array}$ & $\begin{array}{c}\text { improved } \\
\text { more } \\
\text { than } 50 \%\end{array}$ \\
\hline B9A & Manufacturing conformance & 1 & 2 & 3 & 4 & 5 \\
\hline B9B & Product quality and reliability & 1 & 2 & 3 & 4 & 5 \\
\hline B9C & Product customization ability & 1 & 2 & 3 & 4 & 5 \\
\hline B9D & Volume flexibility & 1 & 2 & 3 & 4 & 5 \\
\hline B9E & Mix flexibility & 1 & 2 & 3 & 4 & 5 \\
\hline B9F & Time to market & 1 & 2 & 3 & 4 & 5 \\
\hline B9I & Delivery speed & 1 & 2 & 3 & 4 & 5 \\
\hline B9L & Delivery dependability & 1 & 2 & 3 & 4 & 5 \\
\hline B9M & Unit manufacturing cost & 1 & 2 & 3 & 4 & 5 \\
\hline B9N & Manufacturing lead time & 1 & 2 & 3 & 4 & 5 \\
\hline B9Q & Labour productivity & 1 & 2 & 3 & 4 & 5 \\
\hline B9R & Inventory turnover & 1 & 2 & 3 & 4 & 5 \\
\hline B9S & Capacity utilization & 1 & 2 & 3 & 4 & 5 \\
\hline B9T & Overhead costs & 1 & 2 & 3 & 4 & 5 \\
\hline
\end{tabular}




\section{References}

Amit R, Schoemaker PJH (1993) Strategic assets and organizational rent. Strateg Manag J 14:33-46

Bozarth CC, Handfield RB (2008) Introduction to operations and supply chain management, 2nd edn. Pearson, Upper Saddle River

Cagliano R, Acur N, Boer H (2005) Patterns of change in manufacturing strategy configurations. Int J Oper Prod Manage $25: 701-718$

Cagliano R, Golini R, Caniato F, Kalchschmidt M, Spina G (2008) Supply chain configurations in a global environment: a longitudinal perspective. Oper Res Manag 1:86-94

Carr C (1993) Global, national and resource-based strategies: an examination of strategic choice and performance in the vehicle components industry. Strateg Manag J 14:551-568

Collis DJ (1991) A resource-based analysis of global competition: the case of the bearings industry. Strateg Manag J 12:49-68

Ferdows K, De Meyer A (1990) Lasting improvements in manufacturing performance: in search of a new theory. J Oper Manag 9:168-184

Flynn BB, Flynn EJ (2004) An exploratory study of the nature of cumulative capabilities. J Oper Manag 22:439-457

Goldstein H (1979) The design and analysis of longitudinal studies. Academic, London

Größler A, Grübner A (2006) An empirical model of the relationships between manufacturing capabilities. Int J Oper Prod Manage 26:458-485
Heizer J, Render B (2008) Operations management, 9th edn. Pearson, Upper Saddle River

Ketokivi MA, Schroeder RG (2004) Perceptual measures of performance: fact or fiction? J Oper Manag 22:247-264

Krajewski LJ, Ritzman LP, Malhotra MK (2010) Operations management-processes and supply chains, 9th edn. Pearson, Upper Saddle River

Lapré MA, Scudder GD (2004) Performance improvement paths in the U.S. airline industry: linking trade-offs to asset frontiers. Prod Oper Manag 13:123-134

Leonidou LC (1999) Barriers to international purchasing: the relevance of firm characteristics. Int Bus Rev 8:487-512

Porter ME (1996) What is strategy? Harvard Bus Rev 74(6):61-78

Rosenzweig ED, Roth AV (2004) Towards a theory of competitive progression: evidence from high-tech manufacturing. Prod Oper Manag 13:354-368

Schmenner RW, Swink ML (1998) On theory in operations management. J Oper Manag 17:97-113

Slack N, Lewis M (2002) Operations strategy. Pearson, Harlow

Slack N, Chambers S, Johnston R (2007) Operations management, 5th edn. Prentice Hall, Harlow

Swink M, Way MH (1995) Manufacturing strategy: propositions, current research, renewed directions. Int J Oper Prod Manage $15: 4-26$

Warren K (2007) Strategic management dynamics. Wiley, Chichester

Wheelwright SC (1984) Manufacturing strategy: defining the missing link. Strateg Manage J 5:77-91 